\title{
Effect of low-dose theophylline plus beclometasone on lung function in smokers with asthma: a pilot study
}

\author{
M. Spears*, I. Donnelly\#, L. Jolly\#, M. Brannigan*, K. Ito`, C. McSharry”, J. Lafferty*, \\ R. Chaudhuri*, G. Braganza*, I.M. Adcock ${ }^{\uparrow}$, P.J. Barnes \\ S. Wood ${ }^{+, \dagger}$ and N.C. Thomson*
}

ABSTRACT: Smoking is common in asthma and is associated with worse asthma control and a reduced therapeutic response to corticosteroids. The present authors hypothesised that treating smokers with asthma with low-dose theophylline added to inhaled corticosteroids would enhance steroid sensitivity and thereby improve lung function and symptoms.

In a double-blind, parallel group exploratory trial, 68 asthmatic smokers were randomised to one of three treatments for 4 weeks: inhaled beclometasone $\left(200 \mu \mathrm{g} \cdot \mathrm{day}^{-1}\right)$, theophylline $\left(400 \mathrm{mg} \cdot \mathrm{day}^{-1}\right)$ or both treatments combined. Outcome measures included change in lung function and Asthma Control Questionnaire (ACQ) scores.

At 4 weeks, theophylline added to inhaled beclometasone produced an improvement in peak expiratory flow (39.9 L- $\mathrm{min}^{-1}, 95 \%$ confidence intervals $\left.(\mathrm{Cl}) 10.9-68.8\right)$ and ACQ score $(-0.47,95 \%$ $\mathrm{CI}-0.91--0.04)$ and a borderline improvement in pre-bronchodilator forced expiratory volume in one second (mean difference $165 \mathrm{~mL}, 95 \% \mathrm{Cl}-13-342$ ) relative to inhaled corticosteroid alone. Theophylline alone improved the ACQ score $(-0.55,95 \% \mathrm{Cl}-0.99--0.11)$, but not lung function.

In the present pilot study, the combination of low-dose theophylline and inhaled beclometasone produced improvements in both lung function and symptoms in a group of smokers with asthma. Larger trials are required to extend and confirm these findings.

KEYWORDS: Asthma, corticosteroid insensitivity, histone deacetylase, smoking, theophylline

\section{(1)}

nhaled corticosteroids are recommended as a first-line treatment for chronic persistent asthma [1], although a significant proportion of individuals fail to establish complete control of their asthma despite this approach [2]. Smokers with asthma form part of this poorly controlled group as demonstrated by their increased symptoms [2, 3], increased emergency department visits for asthma [4, 5] and an impaired response to both inhaled and oral corticosteroids [6-9] compared with nonsmokers with asthma. The prevalence of smoking in asthma reflects that of the general population and therefore smokers with asthma comprise a large group of patients with poorly controlled disease [10]. Smoking cessation is an effective intervention for smokers with asthma [11], but as sustained quitting rates are low, additional or alternative therapies are needed for individuals with asthma who smoke.

The anti-inflammatory actions of corticosteroids are mediated, in part, by the recruitment of histone deacetylase (HDAC), a nuclear enzyme involved in the switching off of activated inflammatory genes [12]. Cigarette smoke reduces HDAC activity in vitro [13], which could explain corticosteroid insensitivity in smokers with asthma. At standard doses, theophylline produces bronchodilation, whereas low doses increase HDAC activity with associated reductions in inflammatory gene expression [14]. Therefore, the present authors undertook an exploratory clinical trial to examine the effects of low-dose theophylline in combination with low-dose inhaled corticosteroids and theophylline alone on lung function and other outcomes in comparison with inhaled corticosteroids alone in smokers with asthma.

\section{METHODS}

\section{Subjects}

Mild-to-moderate [1] stable asthmatics aged $18-60 \mathrm{yrs}$ on $\leqslant 1,000 \mu \mathrm{g} \cdot \mathrm{day}^{-1}$ beclometasone (or

\section{AFFILIATIONS}

*Respiratory Medicine,

\#Immunology,

+General Practice, Faculty of

Medicine, University of Glasgow. Glasgow, and

"National Heart and Lung Institute Imperial College, London, UK.

\section{CORRESPONDENCE}

N.C. Thomson, Respiratory Medicine Section, Division of Immunology, Infection and Inflammation, Faculty of Medicine, University of Glasgow and Gartnavel General Hospital, Glasgow, G12 OYN, UK. Fax: 441412113464

E-mail: n.c.thomson@

clinmed.gla.ac.uk

Received:

October 202008

Accepted after revision:

January 072009

SUPPORT STATEMENT

The current study was funded by the Chief Scientists Office (Edinburgh,

Scotland) and Chest, Heart and Stroke (Edinburgh, Scotland).

GlaxoSmithKline acted as sponsor for the trial.

CLINICAL TRIAL

The present study is a registered clinical trial on ClinicalTrials.gov (identifier No. NCT00119496).

STATEMENT OF INTEREST

Statements of interest for I.M. Adcock and P.J. Barnes, and the study itself can be found at www.erj.ersjournals.com/misc/ statements.dtl

Online ISSN 1399-3003 
equivalent), who were current smokers ( $\geqslant 5$ cigarettes $\cdot$ day $^{-1}$ with $\geqslant 5$ pack $\cdot \mathrm{yrs}^{-1}$ smoking history) were eligible for enrolment. All subjects demonstrated reversible airflow obstruction [15]. Exclusion criteria included diabetes, recent myocardial infarction or other active pulmonary diseases (full criteria available at www.clinicaltrials.gov; identifier No. NCT00119496). Patients were recruited from general practice, hospital clinics and research databases. The West Glasgow Research Ethics Committee (Glasgow, UK) approved the study and all patients gave written informed consent.

\section{Study design}

The current study was a randomised, prospective, doubleblind, double-dummy, active comparator, parallel group design. Subjects taking inhaled corticosteroids alone or in combination with inhaled long acting $\beta_{2}$-agonists completed a step-down in therapy during a 6 week run-in period where they were monitored for loss of asthma control. At the end of a 2-week corticosteroid-free period each subject (if deemed to have stable asthma) attended a randomisation visit, which comprised of spirometry, peak expiratory flow (PEF), completion of an Asthma Control Questionnaire (ACQ) [16], induced sputum for differential counts, supernatant and sputum macrophage HDAC activity and bloods for safety (full blood count, renal and liver function testing) and characterisation (total and specific immunoglobulin E).

Subjects were then randomised to one of three arms: 1) $200 \mu \mathrm{g} \cdot$ day $^{-1}$ inhaled hydrofluoroalkane beclometasone dipropionate (Qvar@); IVAX, Runcorn, UK; equivalent to $\sim 400 \mu \mathrm{g} \cdot$ day $^{-1}$ chlorofluorocarbon beclometasone) [17]; 2) $400 \mathrm{mg} \cdot \mathrm{day}^{-1}$ oral theophylline (Uniphyllin ${ }_{\mathbb{R}}$ Continus ${ }^{\circledR}$; NAPP, Cambridge, UK); or 3) $400 \mathrm{mg} \cdot \mathrm{day}^{-1}$ oral theophylline in combination with $200 \mu \mathrm{g} \cdot \mathrm{day}^{-1}$ inhaled beclometasone. Prebronchodilator lung function was re-assessed at 14 days and all tests performed at the randomisation visit were repeated after 28 days with the addition of serum theophylline level.

\section{Measurements}

Lung function assessments conformed to consensus guidelines [15]. Sputum induction, differential count and supernatant analysis were performed as previously stated [11] with minor modifications to optimise HDAC measurement [18]. Sputum macrophages were encouraged to adhere through plating on six well plates for $1 \mathrm{~h}$ at $37^{\circ} \mathrm{C}$ and then processed for HDAC activity using a Fluor-de-Lys ${ }^{\mathrm{TM}}$ assay kit (Biomol International, Exeter, UK) and analysed using fluorimetry. Sputum supernatants were collected for interleukin (IL)-8, myeloperoxidase (MPO) and RANTES/CC chemokine ligand (CCL) 5 measurement using enzyme immunoassays (R\&D Systems, Abingdon; Immundiagnostik, Oxford Biosystems, Oxford; and Invitrogen Ltd, Paisley, all UK, respectively). Theophylline levels were assessed using an automated processing system (ARCHITECT c8000; Abbot Diagnostics, Maidenhead, UK). Continuation of smoking was confirmed by the detection of urinary nicotine metabolites at each visit using the SmokeScreen ${ }^{\mathrm{TM}}$ system (GFC Diagnostics, Bicester, UK). Subjects were regarded as current smokers if their urine cotinine equivalent concentration was $>1.1 \mathrm{mg} \cdot \mathrm{mL}^{-1}$. Treatment compliance was assessed by tablet count, inhaler weight and serum theophylline level.

\section{Statistical analysis}

The reduced response to inhaled corticosteroids in smokers with asthma meant standard power calculations could not be performed. The present study was informed by a previous clinical trial employing oral corticosteroids in smokers with asthma [9]. This resulted in the estimation that 22 subjects per group were needed to detect a $230 \mathrm{~mL}$ difference in forced expiratory volume in one second (FEV1) between the treatment arms and to allow for a $10 \%$ dropout.

The randomisation schedule was generated in blocks using a previously validated system (RandAll) [19]. The primary endpoint was difference in pre-bronchodilator FEV1 between the treatments and beclometasone alone at 4 weeks. The last value obtained was carried forward for analysis. Lung function changes were examined using ANCOVA (incorporating the KENWARD and Roger [20] method for small groups). The level of statistical significance was set at $p<0.05$. No adjustment was performed for multiple comparisons. Parametric data was examined using paired t-testing, two-sided t-testing or ANOVA and nonparametric data with Mann-Whitney or Kruskal-Wallis testing as appropriate.

\section{RESULTS}

A total of 3,895 smokers with asthma were invited to participate between August 2005 and May 2007, of whom 294 gave positive responses. Following telephone screening, visits were arranged for 187 subjects and 91 subjects were randomised (fig. 1). In total, 23 subjects were allocated to the inhaled beclometasone alone and theophylline alone groups and 22 subjects to the combination of theophylline and inhaled beclometasone. In addition, 23 subjects were randomised to receive another treatment not discussed in the present paper. The baseline demographic, clinical (including previous inhaled corticosteroid and long-acting $\beta_{2}$-agonist use) and inflammatory characteristics of each group were well matched (tables 1 and 2). All the lung function and ACQ results presented in the text are changes derived by ANCOVA relative to the inhaled corticosteroid group response.

\section{Lung function}

Theophylline and inhaled beclometasone

After 4 weeks, the subjects treated with the combination of theophylline and inhaled beclometasone demonstrated a significant improvement in morning PEF $\left(39.9 \mathrm{~L} \cdot \mathrm{min}^{-1} ; 95 \%\right.$ confidence interval (CI) 10.9-68.8; $\mathrm{p}=0.008$; fig. 2a) and a borderline significant improvement in mean pre-bronchodilator FEV1 (mean difference $165 \mathrm{~mL}$; 95\% CI -13-342; $\mathrm{p}=0.069$; fig. $2 \mathrm{~b}$ ) and pre-bronchodilator forced vital capacity (FVC; $254 \mathrm{~mL}$; 95\% CI 63-445; p=0.010). After 2 weeks, low-dose theophylline and beclometasone showed a trend for improvement in morning PEF (24.9 L· $\left.\mathrm{min}^{-1} ; 95 \% \mathrm{CI}-1.5-51.2 ; \mathrm{p}=0.064\right)$ and pre-bronchodilator FVC (132 mL; 95\% CI -23-286; $\mathrm{p}=0.094)$. There were no detectable differences in other lung function endpoints (table 3).

\section{Theophylline}

Theophylline alone did not improve lung function except for post-bronchodilator FVC at 4 weeks (304 mL; 95\% CI 5-604; $\mathrm{p}=0.046$; table 3 and fig. $2 \mathrm{a}$ and $\mathrm{b}$ ). 


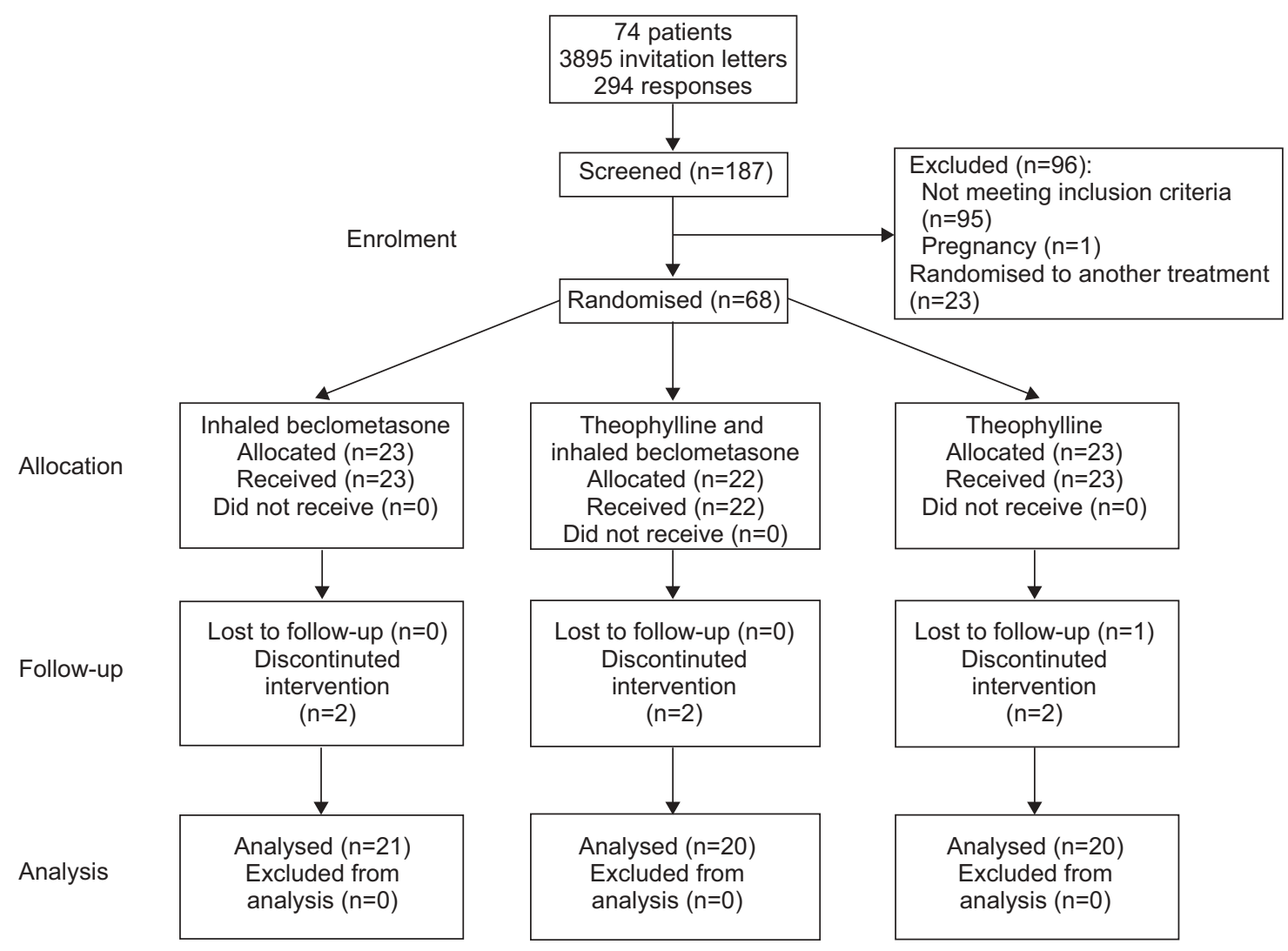

FIGURE 1. Randomisation schedule. Subjects were randomly allocated to one of four treatments and reviewed at 14 and 28 days. Treatment ceased at 28 days. Serious adverse effects: theophylline plus inhaled beclometasone, $n=0$; theophylline, $n=2$ (viral meningitis and chest pain secondary to reflux oesophagitis); inhaled beclometasone, $n=0$,

\section{$A C Q$ score}

After 4 weeks, the combination of theophylline and inhaled beclometasone produced a significant improvement in ACQ score $(-0.47 ; 95 \%$ CI $-0.91--0.04 ; \mathrm{p}=0.033$; fig. 2c and table 3$)$. Theophylline alone also reduced the ACQ score $(-0.55 ; 95 \%$ CI -0.99- -0.11; $\mathrm{p}=0.016$; fig. $2 \mathrm{c}$ and table 3 ).

\section{Sputum samples}

Induced sputum cytology

Overall, 97\% of subjects produced a sample adequate for analysis both pre- and post-treatment. Treatment with the combination of theophylline and inhaled beclometasone was associated with a reduction in the mean absolute $(-10.99 ; 95 \%$ CI -18.15- -1.65; $p=0.018)$ and percentage sputum lymphocyte count (table 3 ). No other relative treatment differences were observed.

\section{Inflammatory biomarkers in sputum}

At 4 weeks, treatment with theophylline alone was associated with a reduction in sputum supernatant IL-8 $\left(-1,201.3 \mathrm{pg} \cdot \mathrm{mL}^{-1}\right.$; 95\% CI -2409.6- -276.6; $\mathrm{p}=0.009)$ and MPO $\left(-215.0 \mathrm{ng} \cdot \mathrm{mL}^{-1} ; 95 \%\right.$ CI -556.0- -36.7; $\mathrm{p}=0.026$; table 3$)$. No difference was detected in RANTES/CCL5 levels following treatment with theophylline and inhaled corticosteroids $\left(-0.131 \mathrm{pg} \cdot \mathrm{mL}^{-}{ }^{1}\right.$; $95 \%$ CI -0.849 0.528). No other significant differences were detectable.

HDAC activity

HDAC activity was measurable for a subgroup within each treatment group (inhaled beclometasone $n=4$, theophylline alone $\mathrm{n}=7$ and theophylline plus inhaled beclometasone $\mathrm{n}=7$ ). Nearly all samples obtained had a low level of HDAC activity. No difference was observed between the groups at baseline or after treatment (tables 1 and 2 and fig. 3).

\section{Serum theophylline levels}

The mean \pm SD serum concentration for the theophylline alone group $\left(4.9 \pm 2.4 \mu \mathrm{g} \cdot \mathrm{mL}^{-1}\right)$ was similar to that achieved in the theophylline and inhaled beclometasone group $\left(4.3 \pm 2.0 \mu \mathrm{g} \cdot \mathrm{mL}^{-1}\right)$.

\section{Compliance}

Overall, $90 \%$ of the subjects who completed the study achieved $\geqslant 80 \%$ compliance with therapy.

\section{Adverse events}

Two serious adverse events occurred during the trial. Both occurred in the theophylline alone arm. One subject was admitted to hospital with viral meningitis, a condition felt to be unrelated to the medication and another with chest pain due to gastro-oesophageal reflux (a pre-existing condition), which was considered as exacerbated by the treatment. Neither subject withdrew from the study. There were two withdrawals due to adverse events. One each in the inhaled beclometasone alone (diarrhoea and vomiting) and theophylline and inhaled beclometasone (headache) arms. The frequency of headache was equal between the groups (six for theophylline and inhaled corticosteroids, seven for theophylline and five for low-dose beclometasone). Gastrointestinal upset was common in the theophylline alone group with 14 episodes being 
TABLE 1 Baseline demographics

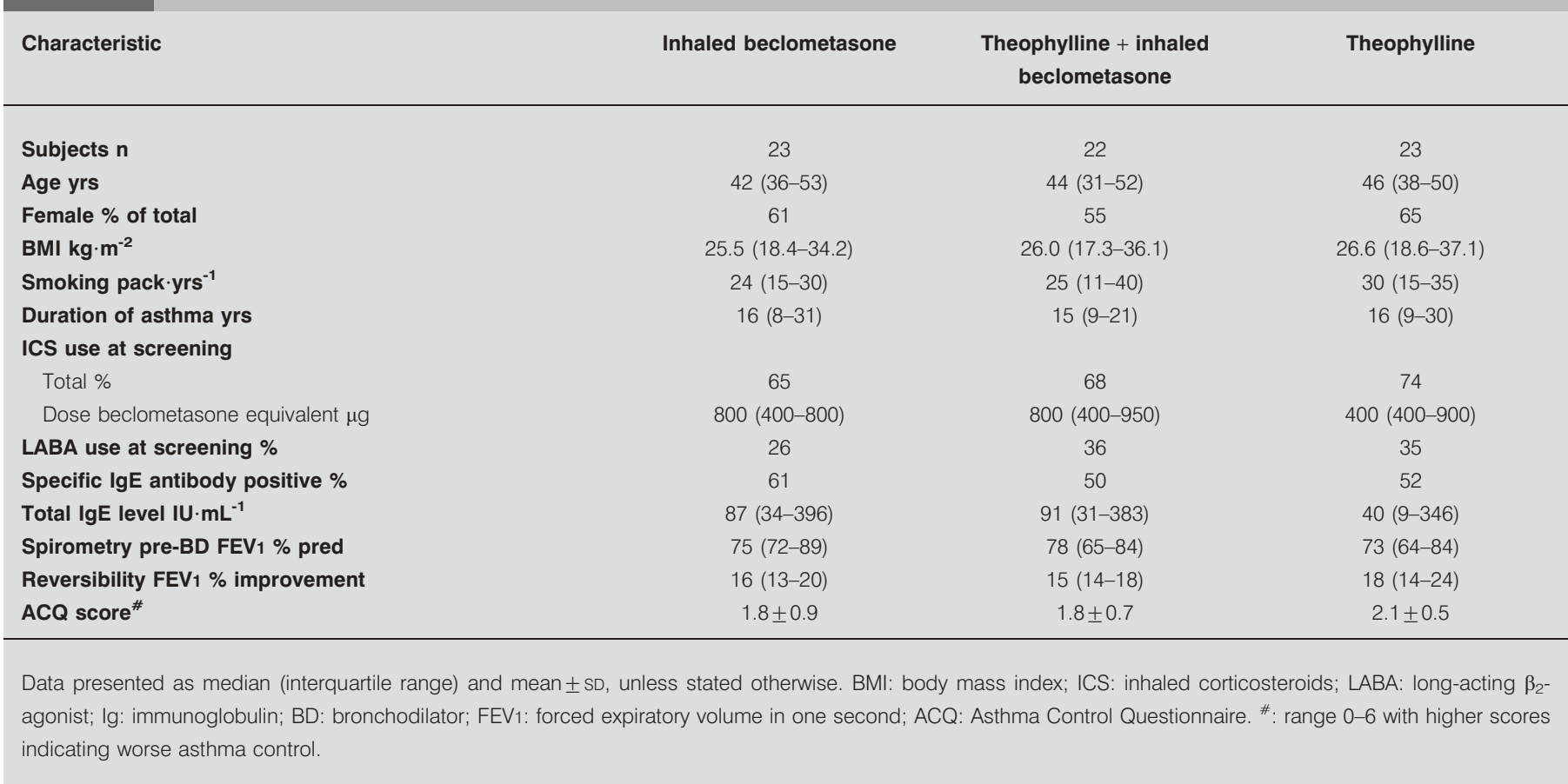

reported. Two subjects reported nausea whilst on theophylline and low-dose beclometasone. Pharyngitis was reported by three subjects in the low-dose beclometasone alone group.

\section{DISCUSSION}

The therapeutic response to inhaled corticosteroids is impaired in smokers with asthma [6-8], highlighting the need for alternative treatment approaches for this large subgroup of asthma patients. Based on previous research [21, 22], it was hypothesised that the addition of low-dose theophylline to inhaled corticosteroid would improve lung function to a greater degree than that produced with inhaled corticosteroid alone. The present study found that the combination of theophylline and inhaled corticosteroid produces improvements in indices of lung function and asthma control score in smokers with asthma.

Treatment with theophylline in combination with inhaled beclometasone for 4 weeks was associated with a large improvement in both pre-bronchodilator PEF and FVC and a borderline significant increase in pre-bronchodilator FEV1. A post hoc power calculation, based on the between patient SD $\left(46.4 \mathrm{~L} \cdot \mathrm{min}^{-1}\right)$ for the theophylline and inhaled corticosteroid group, reveals that 23 subjects per group would be required to

TABLE 2 Baseline sputum counts and histone deacetylase activity (HDAC)

\begin{tabular}{|c|c|c|c|}
\hline Characteristic & Inhaled beclometasone ${ }^{\#}$ & $\begin{array}{c}\text { Theophylline }+ \text { inhaled } \\
\text { beclometasone }\end{array}$ & Theophylline $^{\S}$ \\
\hline Eosinophils \% & $0.9(0.3-1.6)$ & $0.8(0.4-1.8)$ & $1.3(0.5-2.3)$ \\
\hline Absolute count $10^{4}$ cells & $2.1(0.8-5.8)$ & $3.7(1.9-19.5)$ & $6.3(1.7-28.4)$ \\
\hline Neutrophils \% & $25.5(9.6-44.6)$ & $23.5(8.6-42.3)$ & $16.6(8.4-40.3)$ \\
\hline Absolute count $10^{4}$ cells & $184.2(96-437)$ & $271.8(165-452)$ & $78.0(147-729)$ \\
\hline Lymphocytes \% & $1.3(0.6-2.6)$ & $1.6(1.0-2.7)$ & $1.0(0.5-2.5)$ \\
\hline Absolute count $10^{4}$ cells & $4.9(2.3-11.2)$ & $12.4(3.2-20.7)$ & $7.1(1.5-22.6)$ \\
\hline Bronchial epithelial cells \% & $10.5(8.3-15.4)$ & $16.4(8.0-28.9)$ & $12.3(6.1-27.2)$ \\
\hline Absolute count $10^{4}$ cells & $40.7(20.5-99.4)$ & $119.1(63.8-157.6)$ & $83.7(22.1-168.2)$ \\
\hline \multicolumn{4}{|l|}{ HDAC activity ${ }^{f}$} \\
\hline
\end{tabular}

Data presented as median (interquartile range). AFU: arbitrary fluorescence units. ${ }^{\#}: n=10 ;{ }^{\bullet}: n=12 ;{ }^{\S}: n=14 ;{ }^{f}:$ mean $(95 \%$ confidence interval) 

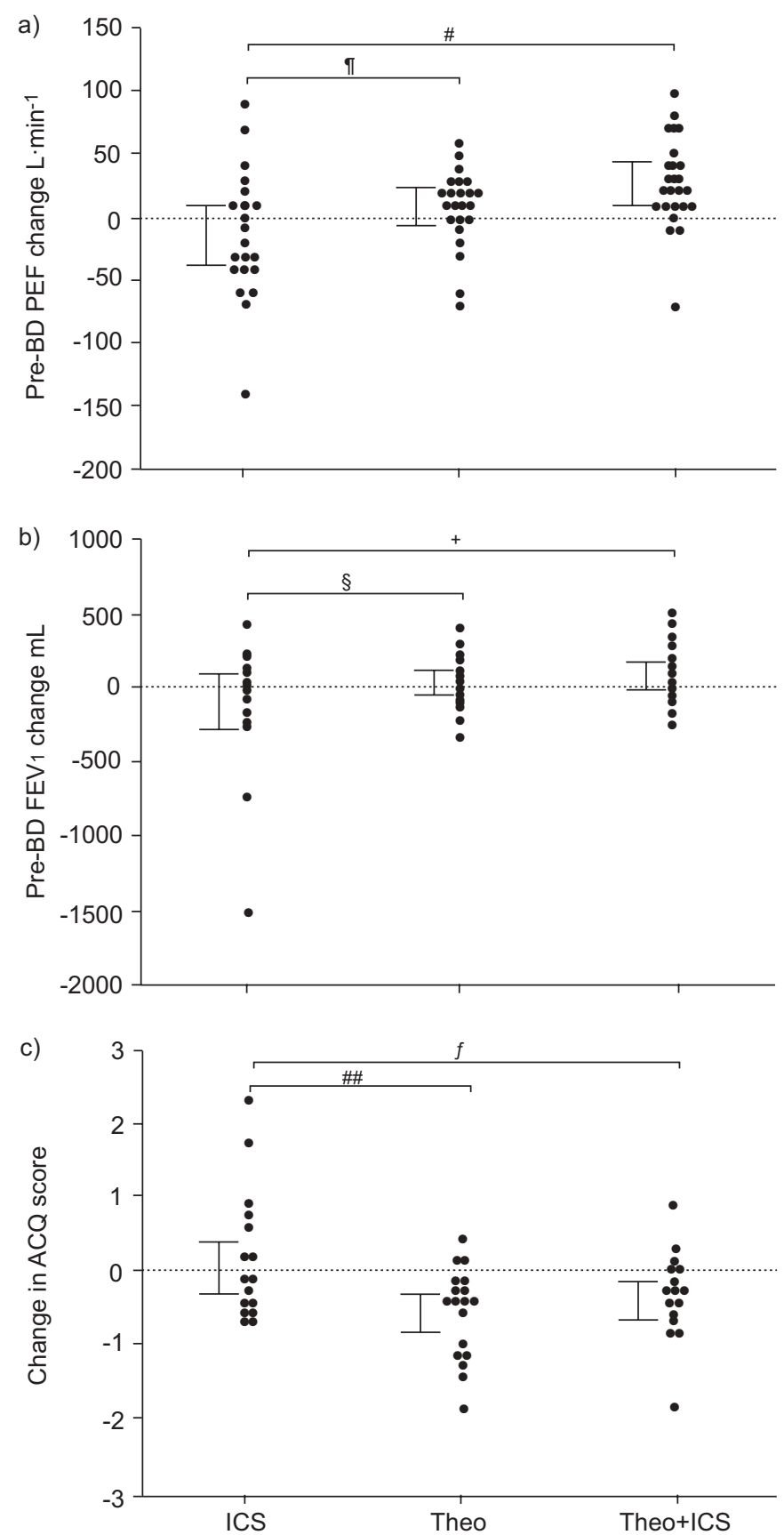

FIGURE 2. Change in a) peak expiratory flow (PEF), b) forced expiratory volume in one second (FEV1) and c) Asthma Control Questionnaire (ACQ) scores from randomisation to 28 days of treatment (paired t-test). Error bars represent $95 \%$ confidence intervals. p-values were derived from comparison of groups with inhaled beclometasone change using ANCOVA. BD: bronchodilator; ICS: inhaled corticosteroids; Theo: theophylline; Theo+ICS: theophylline and inhaled beclometasone combination. ${ }^{\#}: p=0.008 ;{ }^{\top}: p=0.135 ;^{+}: p=0.069 ;{ }^{\varsigma}: p=0.158 ;{ }^{f}: p=0.033$; \#\#: $\mathrm{p}=0.016$.

provide $80 \%$ power for the detection of a $40 \mathrm{~L} \cdot \mathrm{min}^{-1}$ difference in PEF between the combination and inhaled corticosteroid alone groups. The improvement seen in both PEF and FVC (and the associated drop in ACQ score) suggest that the increase in FEV1 in the group treated with low-dose theophylline and inhaled beclometasone is likely to be a real effect. The size of the improvement seen after treatment with low-dose theophylline and inhaled beclometasone is also likely to be clinically significant as it is larger [23] or equivalent [24] to the improvement in PEF seen when long-acting $\beta_{2}$-agonists are added to inhaled corticosteroids in nonsmoking asthmatics. Furthermore, the improvement in PEF demonstrated herein is much larger than that seen with montelukast [8] and high-dose inhaled corticosteroids [7] in previous studies in smokers with asthma. The improvements in lung function with low-dose theophylline and inhaled beclometasone were also associated with a reduction in ACQ score, just below the clinically significant threshold of 0.5 [25]. Given these findings further research should be carried out using low-dose theophylline and inhaled corticosteroids to confirm and extend the current understanding of the efficacy of this combination in smokers with asthma.

Theophylline alone did not produce any significant changes in pre-bronchodilator lung function. Nevertheless, low-dose theophylline treatment did increase post-bronchodilator FVC, produce a clinically significant reduction in ACQ score and a reduction in sputum supernatant cytokines. Previous research has demonstrated that theophylline has a similar effect in subjects with chronic obstructive pulmonary disease [26]. Theophylline has many modes of action including nonspecific phosphodiesterase inhibition and adenosine receptor antagonism [27] and both of these mechanisms could produce bronchodilation. However, the present authors believe that the improvement in lung function with low-dose oral theophylline in combination with inhaled beclometasone is unlikely to be due to a bronchodilating effect of theophylline alone, given the absence of a statistically significant improvement in pre-bronchodilator lung function with low-dose theophylline alone. A previous study has demonstrated superiority for the combination of low-dose theophylline and inhaled beclometasone to high-dose beclometasone alone in nonsmokers with moderate persistent asthma [28]. The present results confirm this finding and conclude that there appears to be a synergistic interaction between low-dose theophylline and corticosteroids in smokers with asthma.

Given the many suggested mechanisms of action of theophylline there are several ways by which low-dose theophylline could synergise with corticosteroids to improve lung function in smokers with asthma. One potential mechanism the current authors attempt to address in this study is the ability of lowdose theophylline to restore HDAC activity. In vitro HDAC activity can be reduced by cigarette smoke and restored by low-doses of theophylline $[13,14]$. Therefore, it was hypothesised that reduced HDAC activity was responsible for the reduced corticosteroid response seen in smokers with asthma and that this could be restored by low-dose theophylline resulting in an improved steroid response. The serum concentration of theophylline achieved in the subjects was within the range previously demonstrated to stimulate HDAC activity. The present authors were not able to confirm an increase in HDAC activity in those subjects treated with theophylline and inhaled corticosteroids despite the subjects being able to produce specimens of sufficient quality for differential counting and supernatant analysis. The reason for this failure was that the number of sputum macrophages 
TABLE 3 Changes in lung function and biomarkers following treatment compared with response to treatment with inhaled beclometasone alone

\begin{tabular}{|c|c|c|}
\hline Change (relative to inhaled beclometasone) & Theophylline + inhaled beclometasone ${ }^{\#}$ & Theophylline \\
\hline \multicolumn{3}{|l|}{ Pre-BD FEV1 mL } \\
\hline Day 28 & $165(-13-342)$ & $128(-51-307)$ \\
\hline \multicolumn{3}{|l|}{ Pre-BD PEF L. $\min ^{-1}$} \\
\hline Day 14 & $25(-1-51)$ & $6(-20-33)$ \\
\hline Day 14 & $132(-23-286)$ & $15(-141-171)$ \\
\hline Day 28 & $254(63-445)^{*}$ & $176(-16-368)$ \\
\hline ACQ score & $-0.47(-0.91--0.04)^{\star}$ & $-0.55(-0.99--0.11)^{*}$ \\
\hline Sputum total cell count cells $\times 10^{6}$ & $-2.0(-6.3-1.7)$ & $-1.7(-6.2-2.1)$ \\
\hline \multicolumn{3}{|l|}{ Sputum eosinophil } \\
\hline \multicolumn{3}{|l|}{ Sputum neutrophil } \\
\hline Absolute $10^{4}$ & $46.8(-65.1-236.2)$ & $-16.0(-199.5-116.1)$ \\
\hline \multicolumn{3}{|l|}{ Sputum macrophage } \\
\hline$\%$ & $0.5(-11.8-11.3)$ & $-2.5(-21.0-15.3)$ \\
\hline Absolute $10^{4}$ & $-52.7(-251.4-118.7)$ & $-0.9(-250.0-186.3)$ \\
\hline \multicolumn{3}{|l|}{ Sputum lymphocyte } \\
\hline$\%$ & $-0.8(-1.4--0.1)^{\star}$ & $-0.6(-1.3-0.2)$ \\
\hline Absolute $10^{4}$ & $-10.99(-18.15--1.65)^{*}$ & $-3.98(-10.30-1.36)$ \\
\hline \multicolumn{3}{|l|}{ Sputum bronchial epithelial cells } \\
\hline$\%$ & $1.2(-5.8-7.4)$ & $-1.0(-11.3-5.7)$ \\
\hline Absolute $10^{4}$ & $-20.9(-85.1-50.5)$ & $-12.9(-100.8-57.3)$ \\
\hline Sputum IL-8 pg $\cdot \mathrm{mL}^{-1}$ & $-562.5(-2131.0-131.4)$ & $-1201.3(-2409.6--76.6)^{\star}$ \\
\hline Sputum MPO $\mathrm{ng} \cdot \mathrm{mL}^{-1}$ & $-126.6(-433.9-58.1)$ & $-215.0(-556.0--36.7)$ * \\
\hline
\end{tabular}

Data are presented as n (95\% confidence interval). Lung function data and Asthma Control Questionnaire (ACQ) score differences are the difference of adjusted means with adjustment for baseline measurement (ANCOVA). Changes in ACQ score, sputum cell counts, supernatant mediator levels and histone deacetylase activity (HDAC) refer to change from randomisation visit to day 28. BD: bronchodilator; FEV1: forced expiratory volume in one second; PEF: peak expiratory flow; FVC: forced vita capacity; IL: interleukin; MPO: myeloperoxidase; AFU: arbitrary fluorescence units. ${ }^{\#}: n=7 ;{ }^{\bullet}: n=7 .{ }^{*}: p<0.05$.

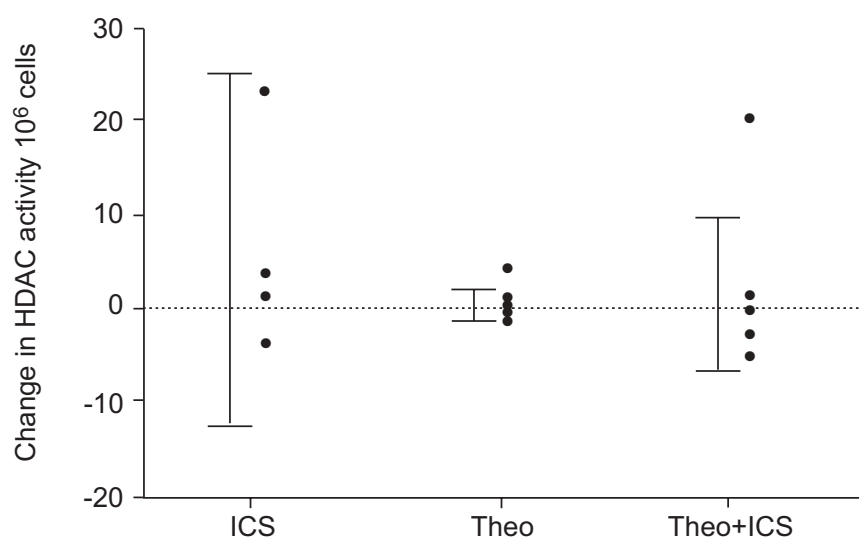

FIGURE 3. Change in histone deacetylase activity (HDAC) from randomisation to 28 days of treatment. Individual plots of HDAC activity are shown. Error bars represent 95\% confidence intervals. ICS: inhaled corticosteroids; Theo: theophylline; Theo+ICS: theophylline and inhaled beclometasone combination. harvested for HDAC was low and thus at the detection limit of the technique. Future investigations examining theophylline in smokers with asthma to address the underlying mechanism/s responsible may need to use bronchoalveolar lavage samples to ensure sufficient macrophages for HDAC analysis. As theophylline can also act as a nonspecific phosphodiesterase inhibitor and an adenosine receptor antagonist, the contribution of these (and other) mechanisms to synergism between theophylline and inhaled beclometasone needs to be examined in smokers with asthma.

In the present study, it was demonstrated that treatment with theophylline and inhaled beclometasone is associated with a reduction in sputum lymphocytes. How this contributes to an improved response to inhaled corticosteroids is unclear. A possible explanation is that the reduction observed is merely due to the group treated with theophylline and inhaled corticosteroids having a slightly higher sputum lymphocyte count at baseline (albeit nonsignificantly different). Previous work addressing the reproducibility of induced sputum counts 
has also demonstrated that sputum lymphocyte counts display lower reproducibility compared with eosinophils and neutrophils [29] so the current authors may be observing the inherent variability of this aspect of induced sputum. However, lowdose theophylline has been demonstrated to reduce airway lymphocyte numbers associated with a reduction in the late asthmatic response to allergen challenge and an alteration in CD4/CD8 T-lymphocyte ratio [30]. Therefore, the reduction in sputum lymphocytes observed may be a true effect.

Finally, apart from the main trial end-point, there were 40 other comparisons made to produce the data presented in table 3. Although it is usual practice to allow for this in the analysis, by performing adjustments of the $\alpha$ value or using $99 \%$ CIs only, unadjusted p-values were presented in the current paper as the study is a pilot (see online supplementary data for results of analysis adjusted for multiple comparisons). The aim has been to identify associations that would need to be examined in future studies.

In conclusion, the current pilot study demonstrates improvements in both lung function and asthma control from the addition of low-dose theophylline to inhaled corticosteroids in a group of smokers with mild-to-moderate asthma. Important questions that need to be addressed in the future include the relative performance of the combination of low-dose theophylline and low-dose inhaled corticosteroids to high-dose inhaled corticosteroids, the effect of lower doses of theophylline and hence the lowest effective dose and the relative performance of the combination of low-dose theophylline and inhaled corticosteroids to the combination of long-acting $\beta_{2}$-agonists and inhaled corticosteroids. Larger trials examining these important management issues should be performed to allow confirmation and extension of the present findings.

\section{ACKNOWLEDGEMENTS}

The present study is dedicated to the memory of S. Wood who died suddenly shortly after the commencement of recruitment. An employee of GlaxoSmithKline blinded to the allocation of the individual patients performed the lung function statistical analysis. The current authors would like to express gratitude to B. Rae (Glasgow, UK) from the Greater Glasgow and Clyde Health Board (Primary Care R\&D) for help and support with this project. The present authors would also like to thank GPs from Greater Glasgow and North and South Lanarkshire (UK) and the volunteers who participated in the study.

\section{REFERENCES}

1 Global Initiative for Asthma. GINA Report, Global Strategy for Asthma Management and Prevention. www. ginasthma.org/Guidelineitem.asp??11 $=2 \& 12=1 \&$ intId $=1561$ Date last accessed: January 6, 2009. Last updated: December, 2008.

2 Bateman ED, Boushey HA, Bousquet J, et al. Can guidelinedefined asthma control be achieved? The gaining optimal asthma control study. Am J Respir Crit Care Med 2004; 170: 836-844.

3 Chaudhuri R, McSharry C, McCoard A, et al. Role of symptoms and lung function in determining asthma control in smokers with asthma. Allergy 2008; 63: 132-135.
4 Lange P, Parner J, Vestbo J, Schnohr P, Jensen G. A 15 year follow-up study of ventilatory function in adults with asthma. N Engl J Med 1998; 339: 1194-1200.

5 Eisner MD, Iribarren C. The influence of cigarette smoking on adult asthma outcomes. Nicotine Tob Res 2007; 9: 53-56.

6 Chalmers GW, Macleod KJ, Little SA, Thomson LJ, McSharry CP, Thomson NC. Influence of cigarette smoking on inhaled corticosteroid treatment in mild asthma. Thorax 2002; 57: 226-230.

7 Tomlinson JEM, McMahon AD, Chaudhuri R, Thompson JM, Wood SF, Thomson NC. Efficacy of low and high dose inhaled corticosteroid in smokers versus nonsmokers with mild asthma. Thorax 2005; 60: 282-287.

8 Lazarus SC, Chinchilli VM, Rollings NJ, et al. Smoking affects response to inhaled corticosteroids or leukotriene receptor antagonists in asthma. Am J Respir Crit Care Med 2007; 175: 783-790.

9 Chaudhuri R, Livingston E, McMahon AD, Thomson L, Borland W, Thomson NC. Cigarette smoking impairs the therapeutic response to oral corticosteroids in chronic asthma. Am J Respir Crit Care Med 2003; 168: 1308-1311.

10 Thomson NC. Smokers with asthma: what are the management options? Am J Resp Crit Care Med 2007; 175: 749-750.

11 Chaudhuri R, Livingston E, McMahon AD, et al. Effects of smoking cessation on lung function and airway inflammation in smokers with asthma. Am J Respir Crit Care Med 2006; 174: 127-133.

12 Barnes PJ, Adcock IM, Ito K. Histone acetylation and deacetylation: importance in inflammatory lung diseases. Eur Respir J 2005; 25: 552-563.

13 Ito K, Lim S, Caramori G, Chung K, Barnes P, Adcock I. Cigarette smoking reduces histone deacetylase 2 expression, enhances cytokine expression, and inhibits glucocorticoid actions in alveolar macrophages. FASEB J 2001; 15 : 1110-1112.

14 Ito K, Caramori G, Cosio M, Chung K, Adcock IM, Barnes P. A molecular mechanism of action of theophylline: induction of histone deacetylase to decrease inflammatory gene expression. Proc Natl Acad Sci 2002; 99: 8921-8926.

15 Standardisation of spirometry - 1987 update. Statement of the American Thoracic Society. Am Rev Resp Dis 1987; 136: 1285-1298.

16 Juniper E, O’Byrne P, Guyatt G, Ferrie P, King D. Development and validation of a questionnaire to measure asthma control. Eur Respir J 1999; 14: 902-907.

17 Vanden Burgt J, Busse WW, Martin RJ, Szefler SJ, Donnell D. Efficacy and safety overview of a new inhaled corticosteroid, QVAR (hydrofluoroalkane-beclomethasone extrafine inhalation aerosol), in asthma. J Allergy Clin Immunol 2000; 106: 1209-1226.

18 Cosio BG, Mann B, Ito K, et al. Histone acetylase and deacetylase activity in alveolar macrophages and blood monocytes in asthma. Am J Respir Crit Care Med 2004; 170: 141-147.

19 Allen A, Down G, Newland A, et al. Absolute bioavailability of intranasal fluticasone furoate in healthy subjects. Clin Ther 2007; 29: 1415-1420.

20 Kenward MG, Roger JH. Small sample inference for fixed effects from restricted maximum likelihood. Biometrics 1997; 53: 983-997. 
21 Ito K, Lim S, Chung KF, Barnes PJ, Adcock I. Theophylline enhances histone deacetylase activity and restores glucocorticoid function during oxidative stress. Am J Repir Crit Care Med 2002; 165: A625.

22 Cosio BG, Tsaprouni L, Ito K, Jazrawi E, Adcock IM, Barnes PJ. Theophylline restores histone deacetylase activity and steroid responses in COPD macrophages. J Exp Med 2004; 200: 689-695.

23 Greening AP, Ind PW, Northfield M, Shaw G. Added salmeterol versus higher-dose corticosteroid in asthma patients with symptoms on existing inhaled corticosteroid. Lancet 1994; 344: 219-224.

24 Bateman ED, Silins V, Bogolubov M. Clinical equivalence of salmeterol/fluticasone propionate in combination (50/ $100 \mu \mathrm{g}$ twice daily) when administered via a chlorofluorocarbon-free metered dose inhaler or dry powder inhaler to patients with mild-to-moderate asthma. Respir Med 2001; 95: 136-146.

25 Juniper E, Svensson K, Mork A, Stahl E. Measurement properties and interpretation of three shortened versions of the asthma control questionnaire. Respir Med 2005; 99: 553-558.

26 Cazzola M, Matera, MG. The additive effect of theophylline on a combination of formoterol and tiotropium in stable COPD: a pilot study. Respir Med 2007; 101: 957-962.

27 Barnes PJ. Theophylline: new perspectives for an old drug. Am J Respir Crit Care Med 2003; 167: 813-818.

28 Evans DJ, Taylor DA, Zetterstrom O, Chung KF, O'Connor BJ, Barnes PJ. A comparison of low-dose inhaled budesonide plus theophylline and high-dose inhaled budesonide for moderate asthma. N Engl J Med 1997; 337: 1412-1419.

29 Pizzichini E, Pizzichini MM, Efthimiadis A, et al. Indices of airway inflammation in induced sputum: reproducibility and validity of cell and fluid-phase measurements. Am J Respir Crit Care Med 1996; 154: 308-317.

30 Jaffar Z, Sullivan P, Page C, Costello J. Low-dose theophylline modulates T-lymphocyte activation in allergen-challenged asthmatics. Eur Respir J 1996; 9: 456-462. 